\title{
Social Informatics in the Future?
}

\author{
Per Flensburg, Arianit Kurti \\ School of Mathematics and Systems engineering, Växjö University, \\ Sweden, per.flensburg@vxu.se, http://w3.msi.vxu.se/ per/ \\ arianit.kurti@vxu.se
}

\begin{abstract}
When Internet in the middle of the 1990s made its breakthrough a revolution occurred compared to the industrial revolution. Suddenly the cost for information transport was reduced to almost zero and genuinely new opportunities arose. Work, that can be performed by unskilled workers, are outsourced and the focus is on the business process. This requires a genuine new way of doing business; we see a need for trust, loyalty, and sharing of values. Education of users at the workplace will be a major concern and a common language and a mutual and deep understanding of the concepts and social contexts used is a prerequisite. A 3D apple model for context is described. For defining the social context, a user centred approach must be used. We need genuinely new informatics paradigms adapted to the network economy. This requires a massive re-education of all workers, both white and blue collar. To sum it all up: Reliable and sustainable production, availability of reliable information, trust, and flexibility are the means for us to survive in this new economy.
\end{abstract}

Keywords: network society, outsourcing, supply chain, Habermas

\section{Introduction}

This paper is not a traditional scientific paper. It is a story presenting our view on the topic of social informatics. As such, it does not follow the traditional scientific form; instead, we have chosen the form of the Catholic mass. That also tells a story and the structure has proven to be sustainable for about 2000 years, which is far beyond the current scientific structure.

We think we have to explain why and how we have decided to use this crazy idea. The first part, Introitus, gives a background and historical reason why social informatics is important. This is seen from a Scandinavian and mainly Swedish perspective. After that comes the Kyrie that describes all the miseries we have seen (well, almost all!). It really indicates that something has to be done. The Gloria part,

Please use the following format when citing this chapter:

Flensburg, P., Kurti, A, 2006, in IFIP International Federation for Information Processing, Volume 223, Social Informatics: An Information Society for All? In Remembrance of Rob Kling, eds. Berleur, J., Numinen, M. I, Impagliazzo, J., (Boston: Springer), pp. 87-96. 
praise the new economy and introduces social informatics as the salvation. The next section, the Credo, describes our beliefs of where we want to go. We strive for this ideal word. Next part is Sanctus; what we have to do in order to achieve what we believe. Finally, we talk about Benedictus, the salvation and the implementation of what we have to do in order to achieve what we believe.

We have chosen this form because the difference between science and religion is not that big, in the end it all boils down to faith [1]. Some has faith in religion and some has faith in Science, still it is faith in both cases. Hence, we chose a structure suitable for faith. That is the reason we have ended up with the mass, despite the fact that none of the authors is religious or a strong believer. Now, let the organ sound and the community enter!

\section{Introitus}

When Internet in the middle of the 1990s made its breakthrough a revolution occurred which in our mind is compared to the industrial revolution. Suddenly the cost for information transport was reduced to almost zero and genuinely new opportunities arose. To understand that, we have to examine the current situation that concerns the economy, industry, and the environment. The information system is only a part of these bigger systems.

Previously there was a focus on rationalisation and making things as cheap, automatic, and efficient as possible. Partly we saw other trends, seeing the computer system as a tool to help people in their work [2]. Sometimes there is awareness about the consequences of the technique, when introduced in society and in companies. Already in 1972, Kristo Ivanov pointed to the fact that the quality of the information can be judge by humans only [3]. At the beginning of the 1970s the ideas of the socio-technique was further developed and put into the trade union conflict oriented framework [4-8]. Internationally, these ideas were supported by a few "crying voices in the desert' [7, 9-13]. In the Manchester, Kolloqvium [14] the specific nature of information systems research was recognised as being non-positivistic and research methods suitable for researching social systems from non-positivistic approaches was approved. The situation of today is however, a misery and here our mass begins.

\section{Kyrie}

\section{The global systems}

Today, Western industry faces the challenge from low paid countries. Work that can be performed by unskilled workers is outsourced. This applies also for programming and systems construction, which are mostly outsourced to India. The Indian programmers are very qualified and can fully compete with our programmers.

In the customer-oriented business of today, much emphasis is placed on low prices, but despite that, the products must have a high quality. With refined production methods and efficient logistic flows, this is possible. We have to keep in 
mind that about $95 \%$ of the time used for production is used for information processing [15] mostly done by human beings. Here is a big potential to cut costs, but at the expense of human work! Less, but more qualified work are left over. Consequently, unemployment will increase as well as the economic gaps. The question is of course: Can we avoid this? If so, how? Let us move on to the next part of the mass.

\section{Gloria}

The usual picture in media today is the picture of the wealthy and healthy young jet set and everybody is sophistically encouraged to join that group of people. The status of the companies is measured in the stock rate leading to a very shortsighted economy, the quarterly economy. So far, this has been a success and unconsciously everybody seems to believe in the infinite growth of the economy. The new Internet economy, with e-business, e-commerce, and other e-phenomena, seems to support this idea since there is no loyalty at the net; leaving a company is as easy as clicking link.

However, some researchers and journalists like $[16,17]$ see another perspective: The competition is hard and it is mainly based on price. It costs much get new customers; a better strategy is keeping the customers you already have. Establishing common values and relationships with the present customers is considered much more important than finding new ones. The advertisements make people suspicious but messages from people they know could make them try a new vendor. We call this the new economy and it is much more based on sustainability than on the old ones. We think this is much more praiseworthy than the capitalistic version. However, the technical development might seemingly point at a different direction. Taking into account the quotation from Rob Kling on the $\mathrm{HCC} 7$ homepage, we realise that we are facing a new social reality and this must create a new vision of the technology.

\section{Credo}

\section{Economy and industry as a whole}

Since IT is dependent on many things, we start in macro scale. We believe there is a growing tendency to outsource, not only IT but as much other functions as possible. For the manufacturing industry, we see a system of suppliers in several tiers. The automotive industry is a good example. Instead of yesterday's gigantic car factories, we see today a set of suppliers design and deliver a specific module of the car according to certain specifications. What counts is the ability to deliver, both in time and in the desired quality. This is a step towards the network economy described in [18-20]. 
The focus is on the business process, not on the single company. This strategy requires a genuine new way of doing business, we see a need for trust, loyalty and sharing of value $[16,21,22]$ instead of the usual increase of benefit.

In Sweden, we see a good economical growth, but we see a decrease in the number of employees due to efficient production. We think this is a worldwide trend, which will have severe effects on the labour market, in addition to creating political instability and conflicts between countries. An example is the upcoming budget negotiation in the EU where the new members expect huge contributions whereas the old members (such as France and Great Britain) are not willing to give up their privileges.

We also believe the current economical focus on short time benefits must be replaced with more sustainable reasoning. Within the manufacturing industry we se a growing focus on sustainability and this must sooner or later, unfortunately probably later, put the focus on more long-term issues.

\section{Implications for information systems}

We have already indicated that about $95 \%$ of the time used in industry is for information processing. We have talked to industrial workers about this situation such as [15], but we have to admit, we have no hard scientific evidence. However, further rationalisation is more likely to be due to better information processing than better production. It is true that certain areas of production such as maintenance require more attention, which will help decrease production costs. However, it is our firm believe that information processing, that is, providing the right information to the right person at the right time at the right place in the right format with the right content and to the right cost [23] is the key to survival of the western industry!

The industry of today must be extremely flexible and able to produce small series with high quality and short lead-time. The business process is almost tailor-made for every transaction and covers many organisations. Having information systems based upon the MIS model with its roots in the 1960s is no longer possible. Neither is it possible to develop new systems in the way prescribed in systems development models, such as for instance RUP [24-26]. Changes occurs very fast leading to very diverse and varying information requirement. The new service oriented architecture [27-29] is one model for doing this that draws considerable attendance. However, in our mind the ontological aspects are not covered sufficiently [30]. One issue we point at is that information requirements and information needs are not always possible to foresee and the only way to be sure to get it right is letting the users do it themselves [31]. Hence, education of users at the workplace will be a major concern as well as development of suitable and comprehensible tools. In both cases a common language and a mutual and deep understanding of the concepts used is a prerequisite.

The meaning of a certain concept and the knowledge thus achieved is based upon the context at hand. The context definitions so far have been related mainly to environmental and task/activity attribute [32-34]; but that is not enough. Context should be related also to personal and cultural attributes as well. We regarded those three contextual attributes as almost independent, the context apple model (Figure 1). 
As an example, we will briefly describe a research project of introducing the mobile contextual service in the library settings. Ten library workers participated in this project. The idea was to 'translate' the social context into the content of the mobile service. We realised that it would not be possible to translate the social context into the content of a new service without using participatory approach, since it is not possible to identify personal/cultural attributes without direct user involvement. The other two attributes can to some extend be identified (using sensor technology, cameras, work descriptions etc.) without direct user involvement. In our library settings, the environmental attributes were known since the location and its attributes were not changing while our efforts were mainly focused in identifying the activity/task and personal/cultural context. Based on a survey we were able to identify that most of the time library workers were dealing with visitors, they provided information about the content of the book. This information was confirmed during individual structured interviews as well. This was core information about their activity/task.

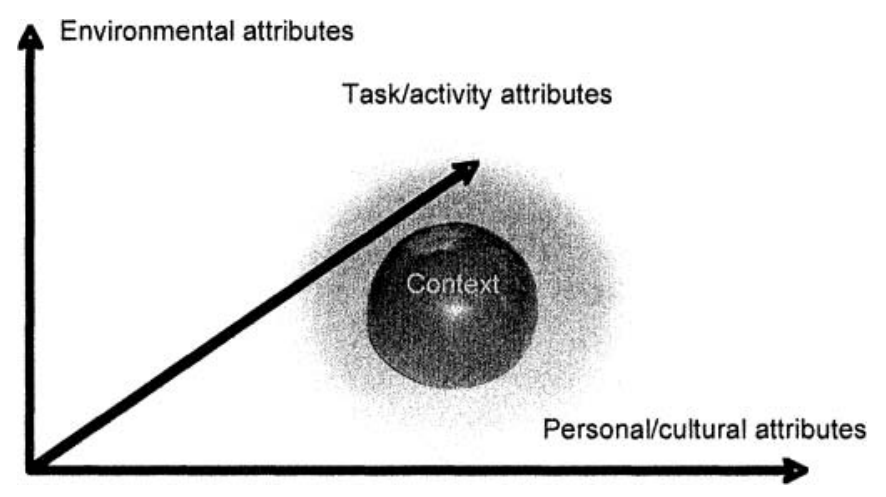

Figure 1 Three attributes of the context, the context apple model.

Based on this and the personal/cultural context (users mobility perception and use), we were able to shape the content of new service. The new service was audio book reviews provided through mobile wireless channels. In our evaluation survey, seven subjects answered that the service would be useful but they would need more time to explore it. One subject answered that yes, it is completely useful and this service should be introduced already next year. Another subject answered that maybe the service might be useful, but it will be difficult to find time and resources to produce the content. The important thing to mention is that none of the subjects answered that the service cannot be useful at all for them even if they had that answer as a possible choice. The explanation was that the users understood the service and identified it as a proposal from them.

Based on this experience we realised that for defining the social context a user centred approach must be used. This is mainly because social context is both complex and unique in the same time, since it contains personal/cultural attributes. These are genuinely human attributes and can be identified only with direct user involvement. The service that has content that correspond to the user social context 
has higher usability and acceptance. This is mainly due to service that is more related and familiar to user social context and due to the user perception of new service and their contribution as well. This was proven correct with the users in our trail project since they have very well accepted the new service.

Therefore, the role of social informatics can be in grasping and mapping the user social context to service content. This process is bidirectional way of learning. We learn from users to understand their social context and users learn from us regarding the service that has content based on their social context.

\section{New informatics domain}

Today, we no longer perform in-house systems development as performed in the 1970 s and the 1980s. The reason is simple. It costs too much (Figure 2).

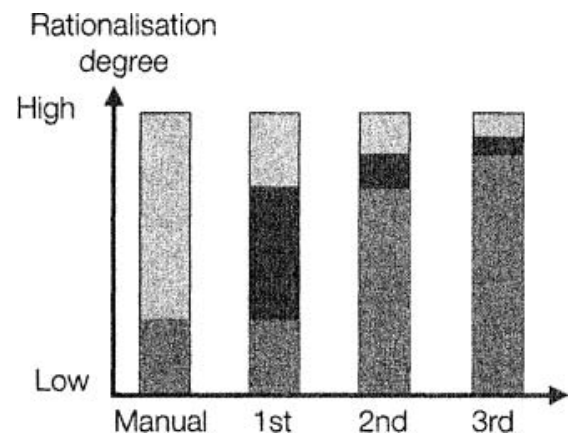

Figure 2 Increase of rationalisation potential for different systems generations [35]

When the first generation of computer-based information systems came into use, the rationalisation potential was very high since the starting point followed manual routines. The tasks that were rationalised were also rather easy because $80 \%$ of the transactions required $20 \%$ of effort. However, when the next generation became involved, the situation was very different. Now the starting point was a high degree of rationalisation so the possible benefit was considerably less. Furthermore, the tasks were trickier and thus the systems development cost was higher. Seen from an economic point of view, it is easy to understand why systems from the 1980 s still are working.

Today, standard systems are used, but they are configured to suite the specific company. The configuration is often cumbersome, tricky, difficult to do, and it takes a long time. SAP/R3 is a well-known application for the complexity of the configuration. However, the drawback occurs when a new release of the standard system becomes available; then the configuration must be done again. The result is the same: IT systems become great hinders for change and they conserve the current work praxis.

The solution to this problem is dividing the BIG systems in smaller, easier to use, understand, and maintain. The needed exchange of information in the network 
society is done with help of Web Services and the whole system is build in a service oriented architecture (SOA), [29]. This architecture is useable for local and even individual systems, provided the users are well enough educated.

However, the network society requires totally new applications and a new way of seeing things [36]. The IT community does not yet identify this in general, but when it is the case, it will be a dramatic change for all IT-processing.

\section{Education}

We have already indicated the need for workplace related education, but we think there will much more need for education in many aspects and in many jobs. After all, the education of our workers is the primary competition weapon! However, we also need education to cope with our complex everyday and to maintain the job carrier. Hence, we will see use of IT, in all forms, for education of people; we will see a society full of applications such as communities, games, chats, and virtual reality. Since we see a growing specialisation of companies, this will also be the case for the business systems. Today we talk about e-health, e-care, e-government, and elearning. Tomorrow, there will be many more and many specialised areas; unfortunately, there is no education for them.

Finally, we believe that this entire phenomenon and many other yet unknown circumstances will lead to an increased discussion of IT and its use and its impact on society. The area of IT in society will become an actual consideration!

\section{Sanctus}

\section{Industry}

Our chance to survive in the current western culture is to lower the production cost, increase the quality, and shorten the delivery time with increased reliability. Besides the production must be more environmental friendly. This seemingly impossible equation is possible due to more efficient and reliable production processes, especially the information processing part. Thus, we can do a flexible production in short series, provided the machinery does not break down. Good maintenance is also a part of the total quality and many will overlook it.

\section{Economy}

We need genuinely new informatics paradigms adapted to the network economy. This requires a massive re-education of all workers, both white and blue collar in order to be able to take advantage of the IT-technologies advantages. It requires also a de-learning with subsequent re-learning of the IT-experts in order to make them think more according to business needs and less according to technical possibilities. One economical advantage, which the manufacturing industry already is aware of, is the fact that sustainable production pays off, not only in reduced environmental load 
but also in tax reduction and selling advantages. The new economy is based upon reliability and trust, manifested in the relation management [16]. They also say that the most valuable asset of the company is its knowledge. An interesting thing is that sharing of knowledge increase it, thus the company should be as open as possible. For conventional economic thinking, this is ridiculous; nevertheless, in the light of trust and reliability, it does make perfect sense.

\section{Critical resources}

To sum it all up: Reliable and sustainable production, availability of reliable information, trust, and flexibility are the means for us to survive in this new economy. How shall we implement it?

\section{Benedictus}

We suggest three different activities that are under implementation in our network. In order to improve industrial production, we must create a research centre dealing with sustainable production and information availability and reliability. Issues addressed by the institute include:

- Decrease information processing time in a supply chain

- Develop IT-systems for total quality maintenance

- Develop sustainable economy models for the network society

- Identify areas where the region industry can compete

- Develop a holistic and sustainable model of production in a local region

The centre is supposed to operate at regional basis and in cooperation with the industries in that region. The specific region we have in mind is southern part of Sweden. This network provides us with companies ${ }^{1}$ willing to join research activities. This is necessary in order to achieve research foundlings from EU or government. With a set of well-known and trusted collaboration partners the base for writing research applications is achieved.

Since companies require very broad competence due to the diversity of their problems, the centre must have access to very broad competence. We can secure this by the second activity: Establishment of a nationwide competence network for research and research education. Here we establish common learning activities with shared teachers and partly shared students. Thus, the researchers know what is going on in the different universities and can draw upon that competence when needed. We also have a greater body of researchers and smart students who can do specific parts of the work. This is supposed to be carried out on mutual base; there is no extra payment and no extra administration.

Now we have companies and we have competence; only the projects are lacking. The process to reformulate company problems is to engage in researchable questions within available competence; we do this in the project formulation phase. We carry this out in another 'centre for project management and innovations', which in fact is

1 'Companies' includes both private and public organisations. 
organised as a course in project formulation and development. During the course the participants (which can be students or researchers) formulates projects and tries to get them founded. In some cases, it will succeed. There is an example from Copenhagen business school, which resulted in nine million DKK!

In doing all three activities, we do hope for beneficiation through many interesting and challenging research projects!

\section{Exodus}

As well as an introitus, we have an exodus - a departure when the community leaves the church. Here it will be close to a combined conclusion and summary. We have drawn a scenario where the future for the western industry is not so very bright, but we have indicated some areas and some ways of doing things where the there might be a brighter future. As far as we can see, taking the use situation into account, focus on the content and the specific, customise instead of standardise is the key success factors. In other words, replace traditional informatics with social informatics!

\section{References}

1. Churchman, C., W, Design of inquiring systems. 1971, New York: Basic Books.

2. Nurminen, M.I., People or computers: three ways of looking at information systems. 1988, Lund, Bromley: Studentlitteratur, Chartwell-Bratt. 202.

3. Ivanov, K., Quality-control of information: on the concept of accuracy of information in data-banks and in management information systems. 1972, Stockholm, [Ca 250] bl. (var. pag.).

4. Bergo, O.T., K. Nygaard, and V. bedriftsklubb, En Evurdering av styrings-og informasjonssystemeet KVPOL. Forskningsrapport fra Norsk Jern- og Metallarbeiderforbunds forskningsprosjekt Nr. 4. 1974, Oslo: Tiden Norsk Forlag. $121 \mathrm{~s}$.

5. Kyng, M. and L. Mathiassen, Computers and design in context. 1997, Cambridge: MIT Press. xvii, $418 \mathrm{p}$.

6. Ehn, P., Work-oriented design of computer artifacts. 1988, Umeå,. 492 (Ca 250 bl.);.

7. Tricker, R.I. and R. Boland, Management information and control systems. 2 nd ed ed. 1982, Chichester: Wiley, xi, $346 \mathrm{~s}$.

8. Kyng, M., G. Bjerknes, and P. Ehn, Computers and democracy: A Scandinavian challenge. 1987, Aldershot: Avebury. 434.

9. Kling, R., The Organizational Context of User-Centered Software Designs. MIS Quarterly, 1977. Vol. 1(Dec77 Issue 4): p. p41, 12p.

10. Greenbaum, J.M., In the name of efficiency: management theory and shopfloor practice in data-processing work. 1979, Philadelphia: Temple Univ. Press. xi, 210.

11. Kling, R., Computerization and controversy. 2. ed. 1996, San Diego: Academic Press.

12. Mumford, E., Values, technology and work. Sijthoff \& Noordhoff series on information systems 3. 1981, The Hague: Nijhoff. x, $318 \mathrm{~s}$.

13. Mumford, E. and D. Henshall, Designing participatively. Repr. ed. 1983, [Manchester]: Manchester Business School. x,191 s.

14. Mumford, E., Research methods in information systems. 1985, Amsterdam: NorthHolland. xii, $320 \mathrm{~s}$.

15. Kallin, S., Meeting with the information logistics group. 2000: Ljungby. 
16. Keen, P.G.W., Relationships - The Electronic Commerce Imperative, in Information Technology and the Future Enterprise,, d.G. Dickson G W, Editor. 2001, Prentice-Hall Inc.

17. Kelly, K., New Rules for the New Economy - 10 ways the network economy is changing everything. 1998, London: Fourth Estate Limited.

18. Castells, M., The Information Age. Economy, Society and Culture, Volume I: The Rise of the Network Society. 1996, Oxford.

19. Castells, M., The Information Age. Economy, Society and Culture, Volume II: The Power of Identity. 1997, Oxford.

20. Castells, M., The Information Age. Economy, Society and Culture, Volume III: End of Millennium. 1998, Oxford.

21. Habermas, J., The Theory of Communicative Action. Vol I: Reason and Rationalization of Society. 1984, London.

22. Habermas, J., The Theory of Communicative Action. Vol II: The Critique of Functionalist Reason. 1988, London.

23. Karlsson, C., P. Flensburg, and S.F. HOl0153rte, Knowledge spillovers and knowledge management. edited by Charlie Karlsson, Per Flensburg, Sven-(O)FFFDke HOl0153rte. 2004, Cheltenham: Edward Elgar. x, 510 p.; ill.

24. Bergström, S. and L. Råberg, Adopting the rational unified process : success with the RUP. Object technology series. 2004, Boston, Mass.; London: Addison-Wesley. xxiii, $245 \mathrm{p}$.

25. Pollice, G., Software development for small teams: a RUP-centric approach. AddisonWesley object technology series. 2004, Boston, Mass.; London: Addison-Wesley; 2003. xxiii, $272 \mathrm{p}$.

26. Kroll, $\mathrm{P}$. and $\mathrm{P}$. Kruchten, The rational unified process made easy : a practitioner's guide to the RUP. Addison-Wesley object technology series. 2003, Boston, Mass. ; London: Addison-Wesley. $\mathrm{xxxv}, 416 \mathrm{p}$.

27. Krafzig, D., K. Banke, and D. Slama, Enterprise SOA : service-oriented architecture best practices. 2005, Indianapolis, IN: Prentice Hall Professional Technical Reference. xxvi, $382 \mathrm{p}$.

28. Newcomer, E. and G. Lomow, Understanding SOA with Web services. Independent technology guides. 2005, Upper Saddle River, NJ ; London: Addison-Wesley. xxxii, 444 p.

29. MacKenzie C M, et al. Reference Model for Service Oriented Architectures Working Draft 10, 15 November 2005. 2005 [cited 2005 Dec 5].

30. Flensburg, P. and M. Milrad. On the Scandinavian Approach in the Network Economy Some Reflections on the Importance of Content and Context. in 26th Information Systems Research Seminar in Scandinavia. 2003. Haikko Manor, Finland, August 9-12 2003.

31. Flensburg, P., Personlig databehandling - Introduktion, konsekvenser, möjligheter (PhD thesis). Lund Studies in Information and Computer Sciences, no 5. 1986, Lund: Studentlitteratur.

32. Park $\mathrm{H}$ and Lee J. A framework of context-awareness for ubiquitous computing middlewares. 2005: IEEE.

33. Zhang D, Chin C, and Gurusamy M. Supporting Context-Aware Mobile Service Adaptation with Scalable Context Discovery Platform. . 2005.

34. Raverdy P and Issarny V. Context-Aware Service Discovery in Heterogeneous Networks 2005: IEEE.

35. Flensburg, P. and S. Friis, Mänskligare datasystem - Utveckling, användning och principer (in Swedish). 1999, Lund: Studentlitteratur.

36. Flensburg, P. Using information systems for collaboration in a network society, in IRIS 25. 2002. Bautahøj, Denmark. 